\title{
Study on a Proper Repair Cycle of Finishing Materials in Condominiums
}

\author{
Tomotaka Ide ${ }^{1}$, Hitoshi Hamasaki ${ }^{2}$ and Yuki Soga ${ }^{3}$ \\ ${ }^{1}$ Shibaura Institute of Technology, Graduate school of Eng. and Sci., 3-7-5 Toyosu, Koto, Tokyo, \\ Japan, me19007@shibaura-it.ac.jp \\ ${ }^{2}$ Shibaura Institute of Technology, School of Arch., 3-7-5 Toyosu, Koto, Tokyo, Japan, \\ hamasaki@shibaura-it.ac.jp \\ ${ }^{3}$ Shibaura Institute of Technology, Graduate School of Eng. and Sci., 3-7-5 Toyosu, Koto, Tokyo, \\ Japan, me18070@shibaura-it.ac.jp
}

\begin{abstract}
In this paper, we discussed the concept for appropriate repair period for finishing materials of reinforced concrete structures. We investigated the actual building repair cycle, the progress of carbonation of concrete, and the adhesion strength of various finishing coating. In addition, we carried out 10-years exposure test of concrete with various finishing to evaluate the progress of carbonation and the degree of deterioration of the finish coating material. From these results, we showed the possibility of extending beyond the current repair cycle.
\end{abstract}

Keywords: Concrete, Finishing Materials, Repair Cycle, Carbonation and Appearance Change.

\section{Introduction}

In order to use reinforced concrete buildings for a long term, it is necessary to regularly repair finishing materials in addition to appropriate daily maintenance. Therefore, in Japan, it is required to make a long-term repair plan for condominiums by law, and the repair plan is designed and executed according to the guidelines ${ }^{1)}$ issued by the Ministry of Land, Infrastructure, Transport and Tourism. However, repair work, especially the recoating of exterior finish materials, has a uniform repair cycle in any condominiums regardless of their age, surrounding environment or type of finishing materials. Previous studies ${ }^{2)-4)}$ pointed out that deterioration speed is different in each material or environment. In other words, in the current repair work may have problems such as deterioration in performance due to leaving the deteriorated part or an increase in extra cost due to the repair of the healthy part. Therefore, in order to efficiently repair work and reduce Life Cycle Cost, it is necessary to set an appropriate repair cycle corresponding to the type of materials, environment and deterioration status.

In this study, we evaluated the current repair cycle by analysing the relationship between the cycle and the deterioration state of existing RC condominiums. Then, we examine the idea of an appropriate repair cycle in terms of performance by verifying the carbonation preventive effects of the finishing materials using the specimen exposed outdoors for 10 years.

\section{Materials and Method}

\subsection{Analysis of Current Repair Cycle and Deterioration State}

In this study, we examined the actual status of finishing materials repair cycle and deterioration states before repair in 222 condominiums around Tokyo, Japan. Based on the deterioration 
diagnosis report, we focused three deterioration index: carbonation of concrete and decrease in adhesion strength of finishing materials and cracks, and examined the actual deterioration state of exterior walls due to differences in factors affecting deterioration (especially age, repair period and directions). For these deterioration phenomena, we calculated the average value, maximum value and standard deviation for each building. In this report, we will report the results of carbonation and adhesion strength.

As shown in Table 1, we classified the finishing materials into three types: mastic, multilayer and single-layer coating, and further classified into eight types by kind of materials.

Table 1. The types of finishing materials and number of condominiums.

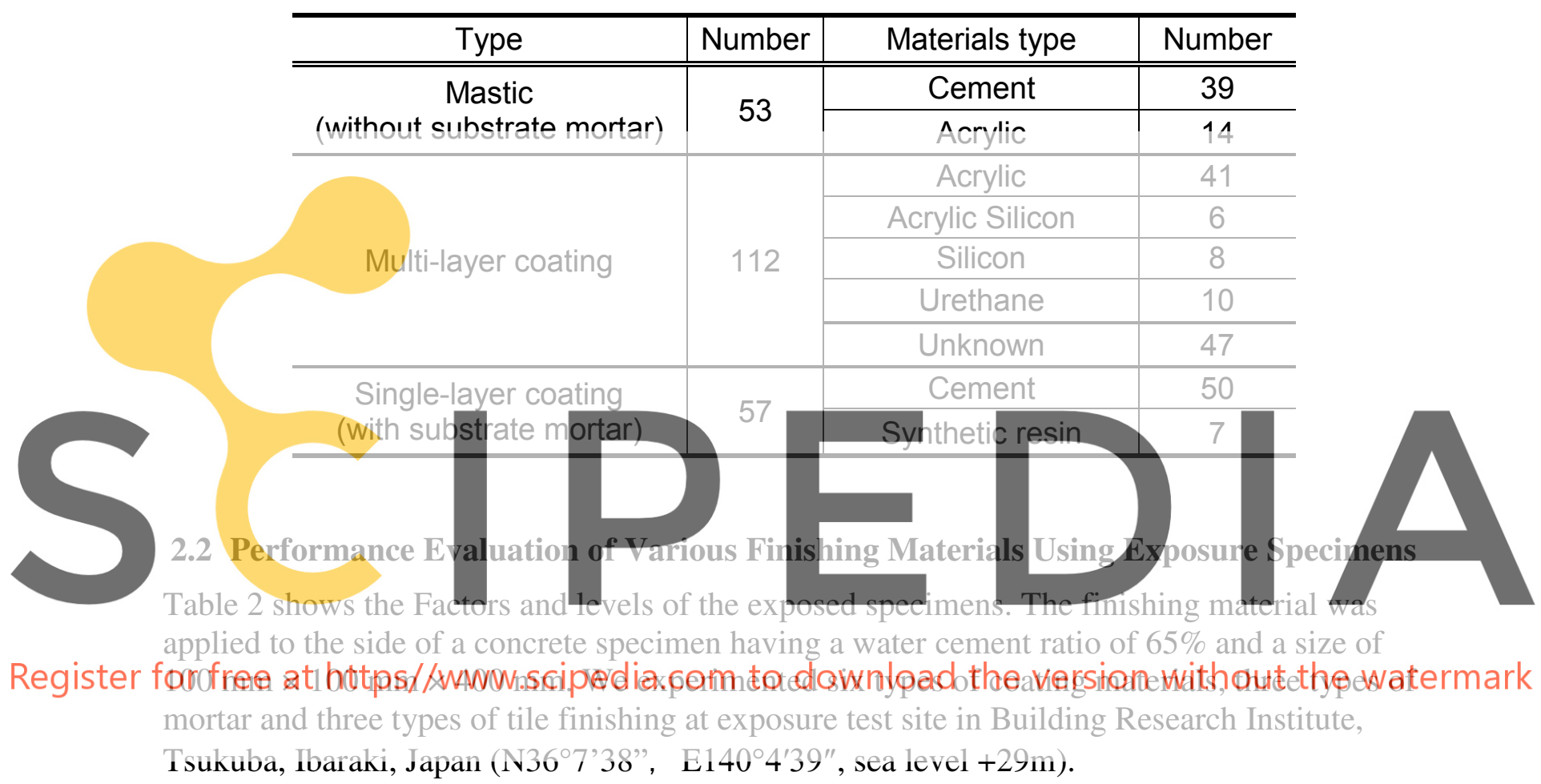

Exposure environment were three types, indoors, outdoors and outdoors under eaves. We measured the carbonation depth and color difference of finishing materials. The color difference $(\Delta E)$ was measured by $L^{*} a^{*} b^{*}$ color coordinates using a colorimeter, and expressed by equation (1) as the difference from the indoor exposure test specimen that seems to be less deteriorated.

$$
\Delta E=\sqrt{\left(L_{o}-L_{i}\right)^{2}+\left(a_{o}-a_{i}\right)^{2}+\left(b_{o}-b_{i}\right)^{2}}
$$

where $\mathrm{L}$ is Lightness, $\mathrm{a}$ and $\mathrm{b}$ are Chromaticity indicating hue and saturation, Subscript $\mathrm{o}$ is Measured value of outdoor exposure test specimen and Subscript $i$ is Measured value of indoor exposure test specimen. 
Table 2. Factors and levels of exposure specimens.

\begin{tabular}{c|c|c}
\hline Factor & \multicolumn{1}{|c}{ Level } \\
\hline \hline $\begin{array}{c}\text { Exposure } \\
\text { environment }\end{array}$ & \multicolumn{2}{|c}{$\begin{array}{c}\text { Indoors, Outdoors (rain / no rain) } \\
\text { Directions (North, East, South and West) }\end{array}$} \\
\hline \multirow{2}{*}{$\begin{array}{c}\text { Finishing material } \\
\text { type }\end{array}$} & Coating & $\begin{array}{c}\text { Synthetic resin (Multi / single) } \\
\text { Waterproof synthetic resin (multi / single) } \\
\text { Gloss paint }\end{array}$ \\
\cline { 2 - 3 } & Mortar & $\begin{array}{c}\text { Cement mortar } \mathrm{t}=10 / 20 \mathrm{~mm} \\
\text { Polymer cement mortar } \mathrm{t}=10 \mathrm{~mm}\end{array}$ \\
\cline { 2 - 3 } & Tile & Mortar $\mathrm{t}=2.0 \sim 3.0 / 10 \mathrm{~mm}$, Adhesive \\
\hline
\end{tabular}

\section{Results and Analysis}

\subsection{Analysis of Current Repair Cycle and Deterioration State}

\subsubsection{Analysis of current repair cycle}

Figure 1 shows the cycle and number of exterior walls repair carried out in 222 condominiums that were analyzed in this study. The cycle was an average of 12 years, with a minimum of 9 years and a maximum of 17 years. More than $70 \%$ of the first repairs were done by the 12 th year. Most of the seconc repairs were carried out after the 12 th year, and the cycle wa than the first repair. Am

30 years old and the thi

Table 4 shows the res

longer. Among them, the single-layer coating had the longest cycle, and the silicon multi-layer

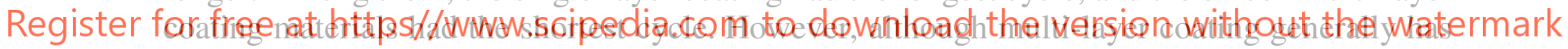
high durability, repair cycle has almost no change regardless of the difference in finishing materials. Accordingly, it indicates that the repair cycle was not set by the type of finishing materials or the degree of deterioration. In other words, it was set by the uniform repair plan.

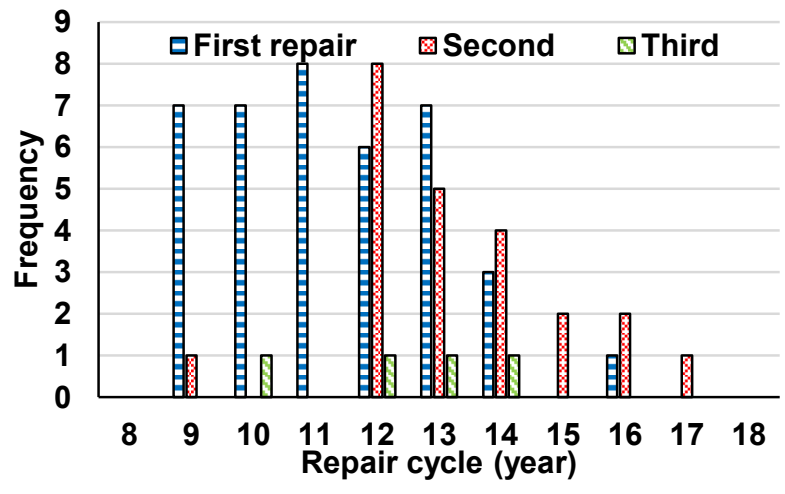

Table 3. Repair cycle for each finishing materials.

Figure 1. Cycle and number of exterior repairs.

\begin{tabular}{c|c|c|c}
\hline Type & $\begin{array}{c}\text { Cycle } \\
\text { (year) }\end{array}$ & Materials type & $\begin{array}{c}\text { Cycle } \\
\text { (year) }\end{array}$ \\
\hline \hline \multirow{2}{*}{ Mastic } & \multirow{2}{*}{11.4} & Cement & 11.3 \\
\cline { 3 - 4 } & & Acrylic & 12.0 \\
\hline \multirow{3}{*}{$\begin{array}{c}\text { Multi- } \\
\text { layer }\end{array}$} & \multirow{2}{*}{11.4} & Acrylic & 11.3 \\
\cline { 3 - 4 } & & Acrylic Silicon & 11.3 \\
\cline { 3 - 4 } & & Silicon & 10.5 \\
\cline { 3 - 4 } $\begin{array}{c}\text { Single- } \\
\text { layer }\end{array}$ & \multirow{2}{*}{12.5} & Urethane & 12.5 \\
\cline { 3 - 4 } & & Cement & 12.3 \\
\hline
\end{tabular}




\subsubsection{Analysis of carbonation preventive effect in existing condominiums}

The following equation can express carbonation coefficient:

$$
A=\frac{C}{\sqrt{t}}
$$

where $\mathrm{A}$ is the carbonation coefficient $\left(\mathrm{mm} /\right.$ years $\left.^{0.5}\right)$; $\mathrm{C}$ is the carbonation depth $(\mathrm{mm})$; $\mathrm{t}$ is the time(years). In this study, we used this $A$ as an index of performance against carbonation.

\subsubsection{Relationship between carbonation and building age (repair cycle)}

Figure 2 shows the carbonation coefficient for condominiums with different ages. Although it shows a few relatively large numbers after approximately 10 years, most of numbers are less than 1.50 after 20-30 years. Previous studies have revealed the relationship between carbonation coefficient and compressive strength in unfinished concrete. ${ }^{5)}$ Assuming that the carbonation coefficient of targeted condominiums is estimated to be about $3.00 \mathrm{~mm} / \mathrm{years}^{0.5}$. Therefore, since the carbonation coefficient was kept low, the carbonation preventive effect has been maintained by repair work for more than 30 years.

Figure 3 shows the carbonation coefficient for each time of repair work. The average carbonation coefficient is about 0.5 to $1.0 \mathrm{~mm} / \mathrm{year}^{0.5}$. On the other hand, the maximum value for the first repair can be confirmed similar value to that of the unfinished concrete. However, in both the second and third repair, the maximum value is significantly lower than the first repair. This is an effect of recoating that the defective part at the time of construction such as

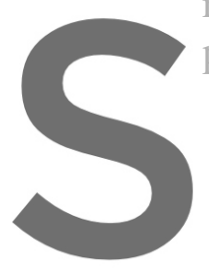
pinhole was repaired.
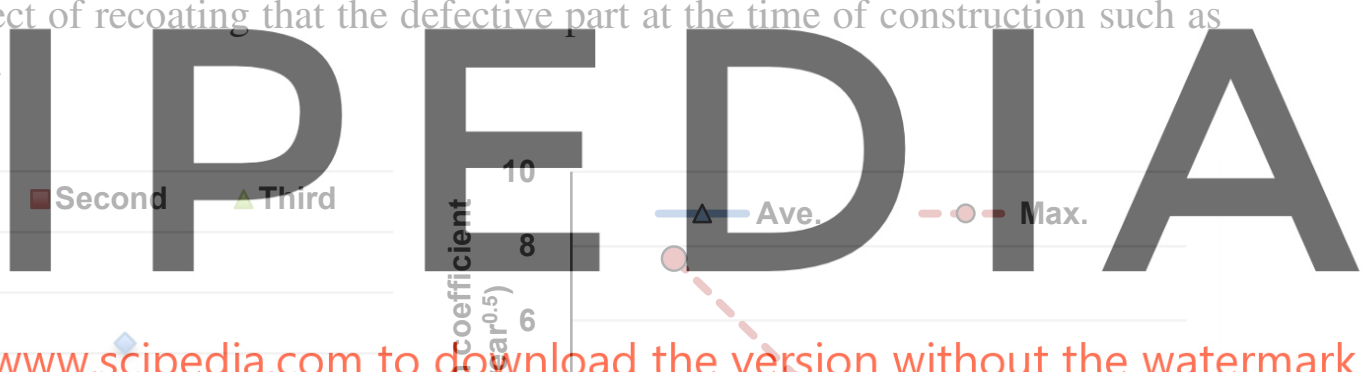

Register fợ ție at https//www.scipedia.com to

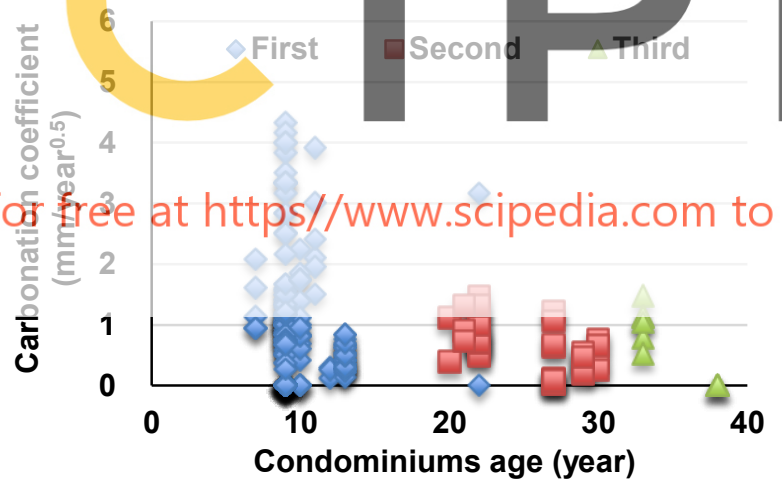

Figure 2. The carbonation speed coefficients for different ages.

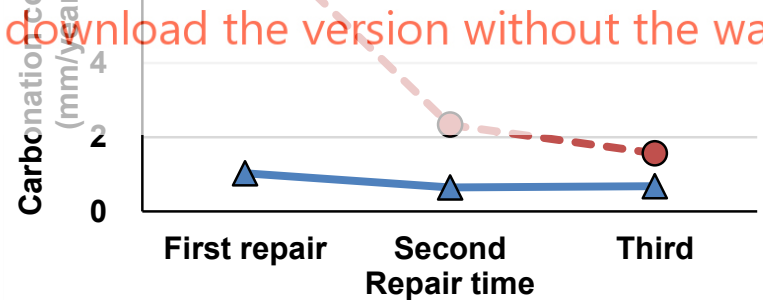

Figure 3. The carbonation coefficients for each repair time.

\subsubsection{Relationship between carbonation and directions}

Figure 4 shows the average of the carbonation speed coefficients for each orientation. The norther and southern sides show slightly larger values than the eastern and western surfaces, especially with thin coating materials. The southern surface has the highest amount of solar radiation, so it is possible that it is more susceptible to UV degradation than other surfaces. In addition, it is known that neutralization is more likely to proceed with dry concrete. In other words, the southern side was in an environment where it was easy to carbonate due to the prolonged dryness caused by solar radiation. According to this result, there is an orientation in 
which the deterioration of the finishing material tends to proceed. On the other hand, the reason for the high numerical value on the north surface is unclear, so we analyzed further about relationship between carbonation and orientation in the exposure test conducted in 3.2.

\subsubsection{Relationship between adhesion strength and repair cycle}

Figure 5 shows the average adhesion strength for repair cycle. Mastic and multi-layer adhesion strength almost did not deteriorate. However, single-layer coating strength deteriorate, and seem to decline below $0.3-0.5 \mathrm{~N} / \mathrm{mm}^{2}$ that is established as quality standards of single-layer coating in Japanese Industrial Standards ${ }^{6}$ after about 17 years. On the other hand, their strengths were maintained above quality standards in JIS until around 15 years.
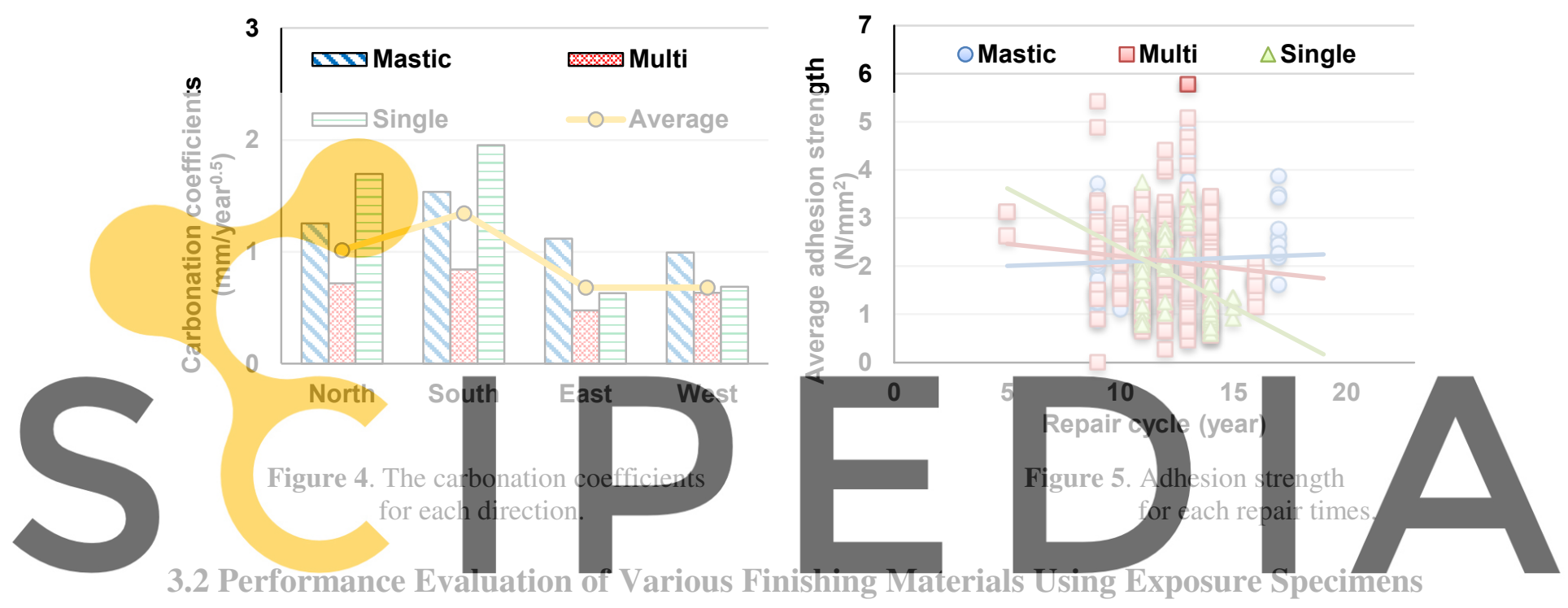

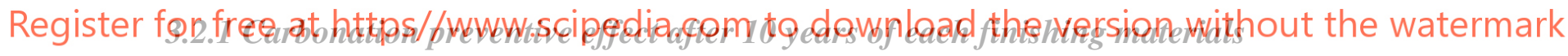

Figure 6-8 shows the carbonation coefficients for each finishing materials in each environment (left side) and each direction (right side). The carbonation coefficients of None finishing concrete was $4.56 \mathrm{~mm} /$ years $^{0.5}$ indoor, $1.95 \mathrm{~mm} /$ years $^{0.5}$ outdoor with rain, and $5.00 \mathrm{~mm} /$ years $^{0.5}$ outdoor under eaves. Therefore, we considered these values as each evaluation standard for the carbonation preventive effect of the finishing materials.

In the case of outdoors with rain, the single-layer coating is $1.89 \mathrm{~mm} / \mathrm{years}^{0.5}$, which is almost same value as none finishing one. This is because the single-layer coating has almost no carbonation suppressing effect, rather than due to deterioration. On the other hand, even with the synthetic resin type materials, multi-layer coatings and waterproof ones had a certain preventive effect. Similarly, even in the case of no rain, the single-layer coating shows a higher value than other finishing materials.

In other materials, mortar $10 \mathrm{~mm}$ and tile on substrate $2.0-3.0 \mathrm{~mm}$ mortar showed relatively high values outdoors without rain. However, the mortar $10 \mathrm{~mm}$ has low value outdoors with rain. This is because the specimen outdoor with rain was supplied with water by rain. It caused a high moist state in a specimen and the mortar became denser because the hydration reaction of the cement progressed. Therefore, the high carbonation coefficient of $10 \mathrm{~mm}$ mortar outdoors 
without rain did not cause by deterioration.

Outdoors with rain, the carbonation preventive effect of most finishing materials was maintained except for the single-layer coating, so they had no deterioration of performance for coating materials, mortars and tiles by 10 years. From these results, it is possible to extend the repair cycle because the current cycle is not at the limit of performance in about 12 years. However, as the data for 10 years cannot mention how long we extend it, further exposure testing is necessary. Moreover, since we handled only synthetic resin type in the coating materials this time, we have to evaluate other coating materials.

Further, although the finishing materials are hardly deteriorated indoors, the tendency that the carbonation of the thin coating $\mathrm{E}$ was high, and the others were low is the same in this case.

\subsubsection{Relationship between carbonation and orientation}

The high values on the northern and southern sides of thin coating material $\mathrm{E}$ was similar to the survey results in 3.1. Especially on the northern side, it was much larger than the value of none finishing concrete. On the other hand, other materials had the small variation in each orientation and the deterioration has not been promoted by direction.

\subsubsection{Analysis of color difference}

Figure 9 shows the color difference of coating material specimens exposed outdoors. In an environment with rain, the color difference is large overall, especially in the single-layer coating. In general, the evaluation standards of color difference, people cannot identify collor difference when it is lower than 3 . as a different color whe environment with rain materials under eaves were lowe coating progress in under eaves, the change in appearance did not necessarily match the

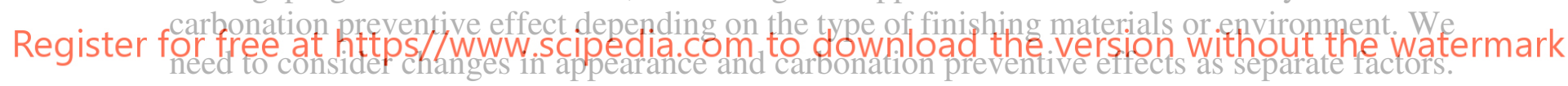
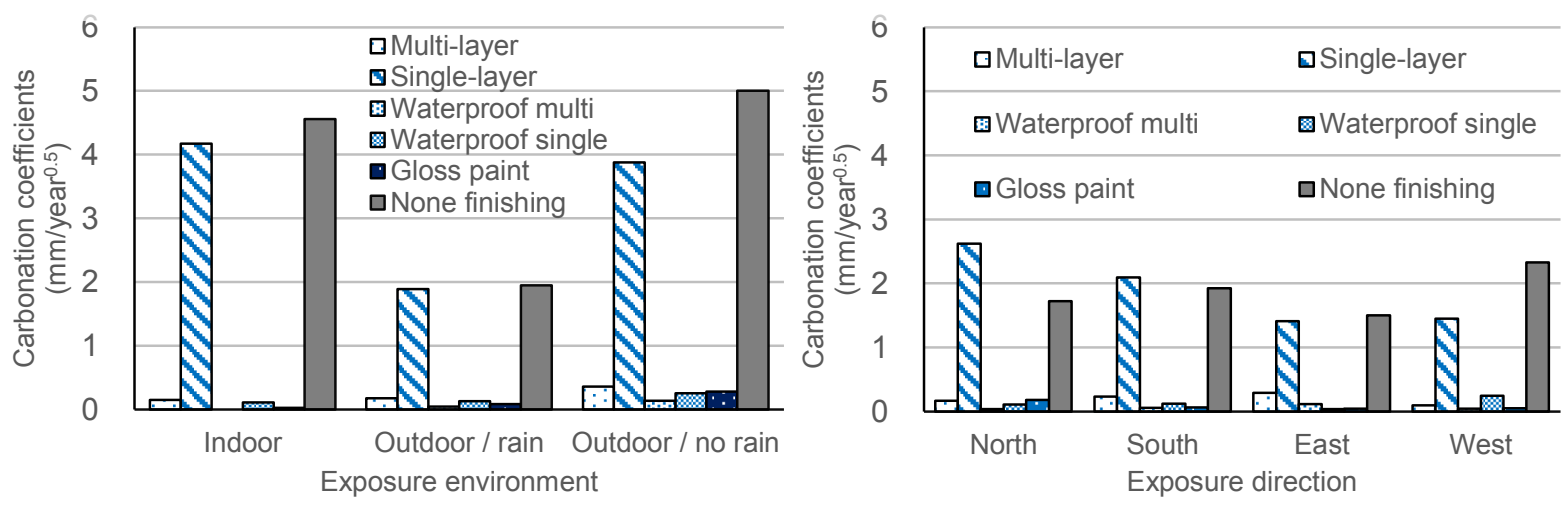

Figure 6. The carbonation coefficients after 10 years (Coating material). 

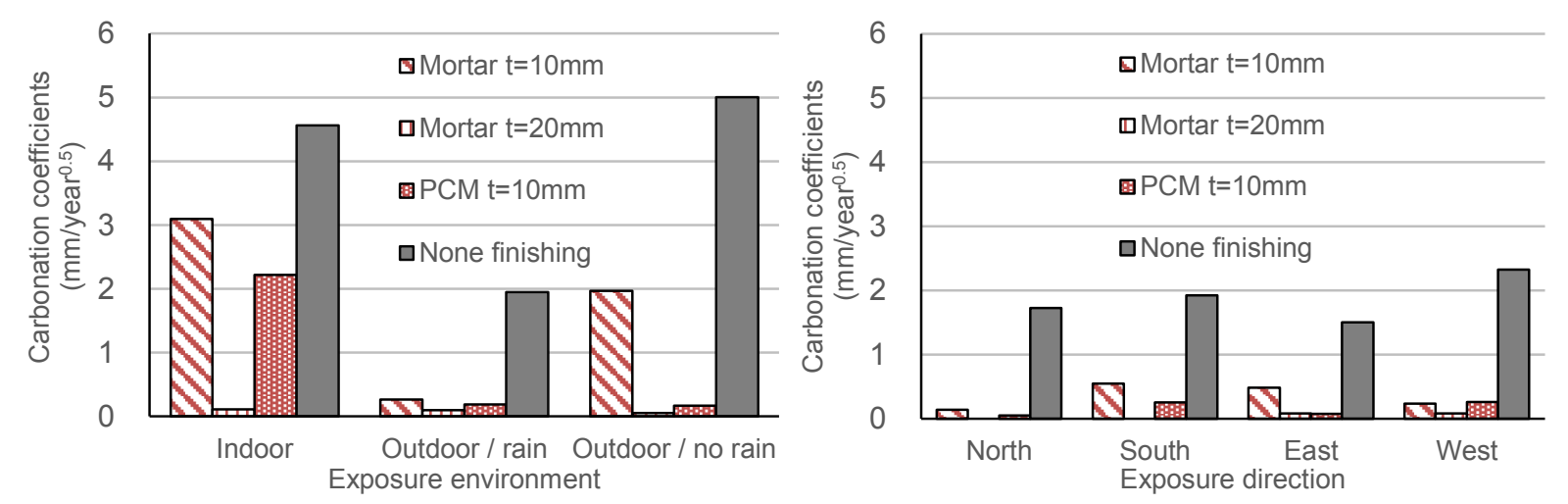

Figure 7. The carbonation coefficients after 10 years (Mortar).
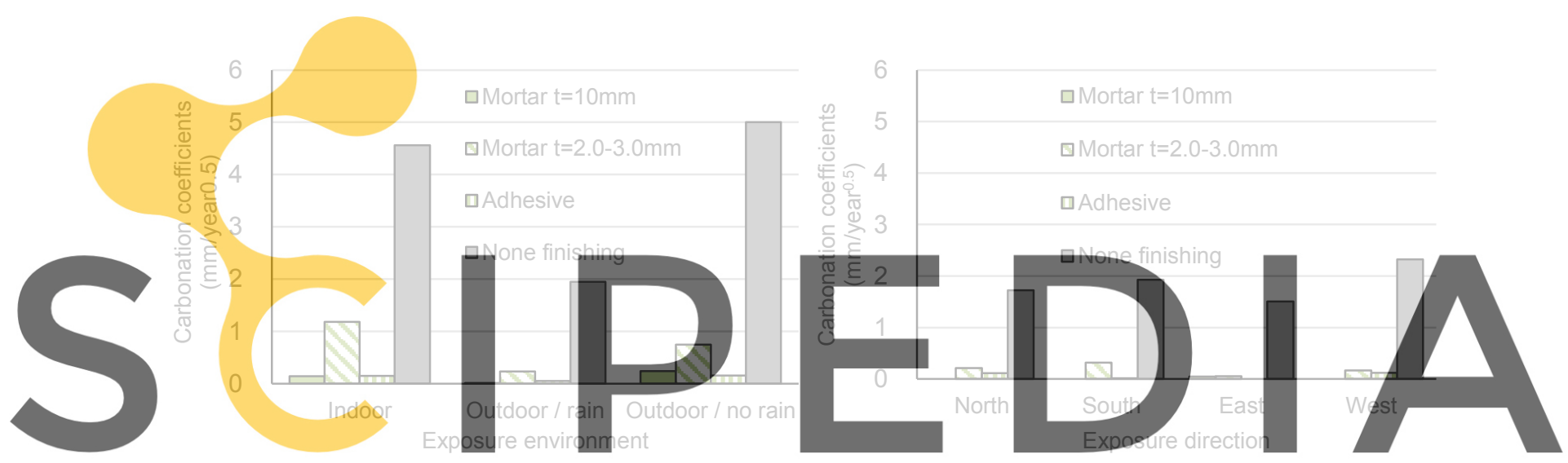

Figure 8. The carbonation coefficients after 10 years (Tile).

Register for free at https//www.scipedia.com to download the version without the watermark

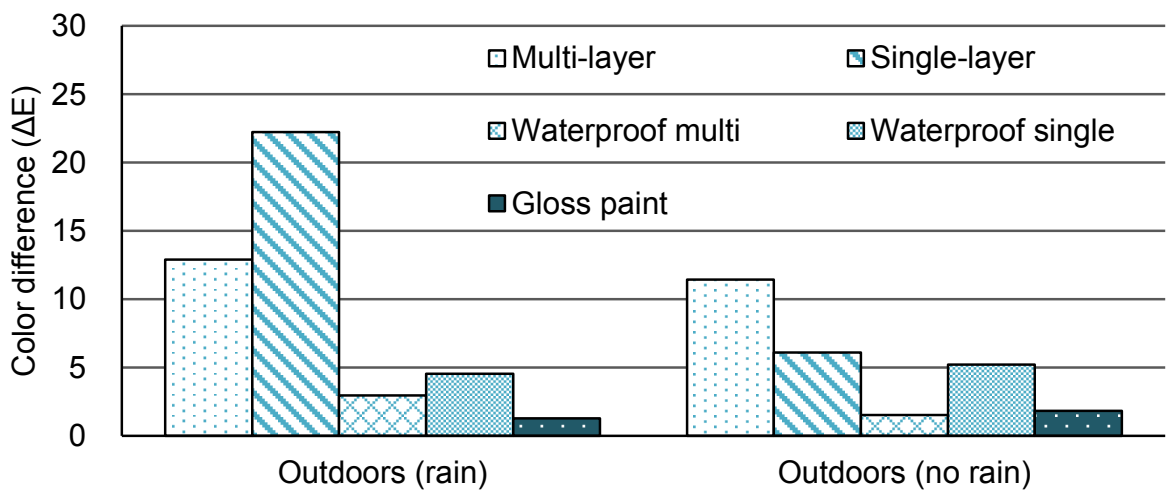

Figure 9. The color difference after 10 years (Coating material). 


\section{Conclusion}

In this study, in order to examine the appropriate repair cycle of exterior finishing materials, we investigated and analyzed the current repair cycle and deterioration state, and second we evaluated the carbonation preventive effect of the finishing materials by using specimens exposed for 10 years. As a result of the survey, the current repair cycle was about 12 years, but since the carbonation preventive effect was sufficiently maintained at the time of repair, the repair cycle may be longer than the current cycle in terms of performance. Furthermore, in the exposed specimens, the single-layer coating had no carbonation preventive effect, but other materials still have the carbonation preventive effects at 10 years, and almost no difference of carbonation in each direction. In the previous study that conducted an outdoor exposure test for 20 years in model building ${ }^{7)}$, the multi-layer coating had had the carbonation preventive effect even after 20 years.

While the finishing materials had not reached their performance limit, repairs may be done from an aesthetic point of view. In particular, appearance of coating materials in an environment with rain relatively changed more than under eaves them after 10 years. Therefore, we need to consider changes in appearance and carbonation preventive effects as separate factors. We will continue the exposure test for more long term to confirm the performance (the carbonation preventive effect, deterioration of coating itself and aesthetics) of each material at various environment.

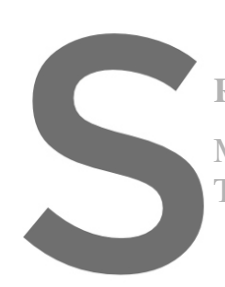

References
Ministry of Land, Infrastructure and Transport (2008). The
Takuya Hasegawa et al. (2002). A study on the Corrosion
$\quad$ model building at the age of eleven years (in Japanese, Architectural Institute of
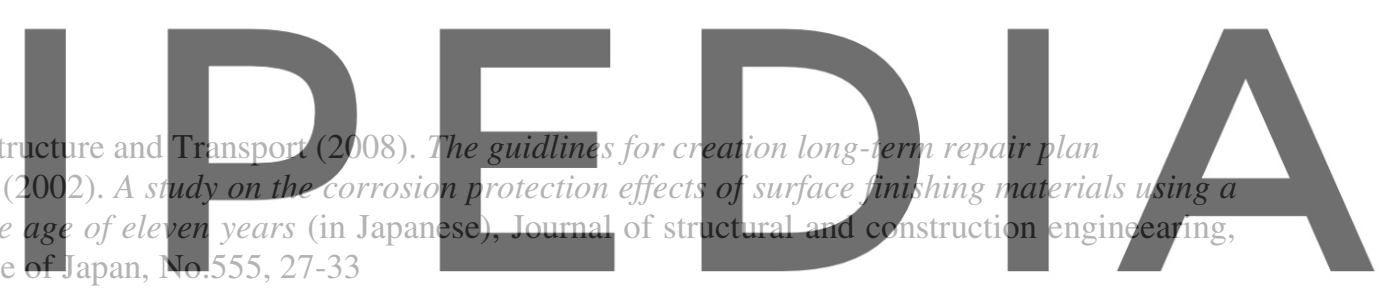

Takuya Hasegawa et al. (2002). A study on the carbonation protection effects of surface finishing materials using

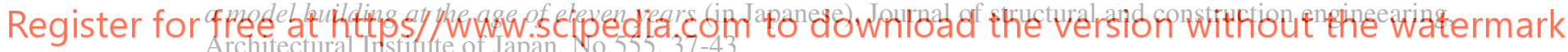

Takuya Hasegawa et al. (2006). A study on the carbonation preventive effects of coating materials for textured finishes of buildings (in Japanese), Journal of structural and construction engineeaning, Architectural Institute of Japan, No.609, 23-30

Taichiro Kawanishi et al. (2006). Analysis on the carbonation of concrete based on investigation of exisiting buldings (in Japanese), Journal of structural and construction engineearing, Architectural Institute of Japan, No.608, 9-14

JIS: Japanese Industrial Standards (2010).JIS A 6909: Coating materials for textured finishes of buildings

Takuya Hasegawa et al. (2017). Deterioration and preventive effects of finishing materials against carbonation and corrosion of reinforcing bars in concrete based on twenty year outdoor exposure test using model building (in Japanese), Journal of structural and construction engineearing, Architectural Institute of Japan, No.733, $337-346$ 